\title{
Inhibitor of Nitric Oxide Synthesis Reduces Hypoxic-Ischemic Brain Damage in the Neonatal Rat
}

\author{
YASUSHI HAMADA, TAKAHIRO HAYAKAWA, HARUO HATTORI, AND HARUKI MIKAWA
}

Department of Pediatrics, Faculty of Medicine, Kyoto University, Kyoto, Japan

\begin{abstract}
We evaluated the neuroprotective effect of the nitric oxide synthesis inhibitor, $N^{G}$-nitro-L-arginine in a neonatal hypoxic-ischemic rat model. Unilateral hypoxicischemic injury was produced in the brain of 7-d-old rats using a combination of a common carotid artery ligation and a hypoxic (8\% oxygen) exposure for $2.5 \mathrm{~h}$. In our experimental condition, rectal temperatures did not differ between $N^{G}$-nitro-L-arginine-treated and saline-injected pups. We killed the animals $72 \mathrm{~h}$ later and assessed the hypoxic-ischemic brain damage histologically. $N^{\boldsymbol{C}}$-nitro-Larginine $(2 \mathrm{mg} / \mathrm{kg})$ administered intraperitoneally $1.5 \mathrm{~h}$ belore hypoxia resulted in $77 \%$ reduction of the infarcted hemispheric volume and $87 \%$ reduction of the infarcted striatal volume compared to saline injected controls. $N^{\boldsymbol{G}}$. nitro-L-arginine given $1.5 \mathrm{~h}$ before the insult also significantly prevented hypoxic-ischemic damage in the five hippocampal structures examined, dentate gyrus, $\mathrm{CA4}, \mathrm{CA} 3$, CA1, and subiculum. $N^{G}$-nitro-L-arginine administered immediately after hypoxia did not prevent hypoxic-ischemic brain damage. These results indicate that nitric oxide plays a key role in producing neonatal hypoxic-ischemic brain damage. (Pediatr Res 35: 10-14, 1994)
\end{abstract}

\section{Abbreviations}

NMDA, N-methyl-D-aspartate

NO, nitric oxide

NOARG, $N^{\boldsymbol{G}}$-nitro-L-arginine

Hypoxia-ischemia increases the extracellular concentration of endogenous excitatory amino acids, which trigger a cascade of biochemical events, such as protease, lipase, and protein kinase $C$ activation; free radical formation; and uncoupling of oxidative phosphorylation within mitochondria via an increase in free cytosolic $\mathrm{Ca}^{2+}$; this cascade ultimately leads to neuronal death (1). NMDA, a glutamate receptor agonist, plays a major role in the production of hypoxic-ischemic brain damage in the immature rat. Among the excitatory amino acid agonists, intracerebral injection of NMDA produces the greatest degree of brain injury in 7-d-old rats [for review see (2)]. The hypoxic-ischemic brain damage in immature rats is identical in appearance and time course to the cytotoxic reaction to NMDA (3). MK-801 [(+)-5methyl-10,11-dihydro-5H-dibenzo[a,d]cyclohepten-5,10-imine maleate], a noncompetitive NMDA antagonist, protects against hypoxic-ischemic brain damage in neonatal rats (4).

NO, a free radical gas, is synthesized by the vascular endothe-

Received February 15, 1993; accepted August 27, 1993.

Correspondence: Yasushi Hamada, M.D., Department of Pediatrics, Faculty of Medicine, Kyoto University, 54 Kawahara-cho, Shogoin, Sakyo-ku, Kyoto 606, Japan. lium in the conversion of L-arginine to L-citrulline by the enzyme NO synthase (5), whose activity has also been reported in forebrain homogenates (6). NMDA stimulates NO synthesis (7), and NO mediates glutamate neurotoxicity in vitro (8). NOARG, an analog of L-arginine, competitively inhibits the enzymatic formation of NO both in cultured endothelial cells (9) and cerebellar homogenates (10), also prevents neurotoxicity induced by NMDA in cortical cultures (8), and easily crosses the blood-brain barrier (10).

Contradictory reports concerning the possible neuroprotective effect of NO synthesis inhibitors in adult models (11-16) prompted us to investigate whether NO was related to the genesis of cerebral hypoxic-ischemic brain damage in neonates. Sevend-old rats were subjected to unilateral carotid artery ligation followed by hypoxic exposure. This neonatal rat model shows infarction of the cerebral hemisphere ipsilateral to the carotid artery ligation (17), and has been frequently used to investigate the pathogenesis of cerebral hypoxia ischemia (for review see Refs. 1 and 18). We investigated the neuroprotective effect of NOARG administered before and after a hypoxic insult.

\section{MATERIALS AND METHODS}

We used the method of Rice et al. (17) to produce hypoxicischemic brain damage in neonatal rats. On the day of surgery, 7-d-old Std:Wister rat (Japan SLC, Inc.) littermates (the day of birth is defined as d 1) were paired according to sex and body weight $( \pm 0.5 \mathrm{~g})$, each pair consisting of a pup assigned to NOARG treatment and a saline-injected control. If one member of a pair died, the other member was discarded. Under ether anesthesia, the left carotid artery was exposed through a midline neck incision, doubly ligated, and severed between the two ligatures. After surgery, the rat pups were allowed to recover for 2.5 to $3.5 \mathrm{~h}$, and at the same time were fasted for $3.5 \mathrm{~h}$ before hypoxic exposure by separating them from their dams.

Hypoxic exposure was achieved by placing littermates $(8-10$ pumps) in a $2.0-\mathrm{L}$ air-tight plastic box submerged in a $37^{\circ} \mathrm{C}$ water bath and flushed for $2.5 \mathrm{~h}$ with a humidified $8 \%$ oxygen and $92 \%$ nitrogen mixture delivered at $1.1 \mathrm{~L} / \mathrm{min}$. After $1 \mathrm{~h}$ recovery in the $37^{\circ} \mathrm{C}$ water bath, they were returned to their mothers until killed at the age of $10 \mathrm{~d}$.

The effect of NOARG was assessed in the two groups, each consisting of pairs from at least three litters. In the prehypoxic treatment group (group $1, n=12$ pairs), $2 \mathrm{mg} / \mathrm{kg}$ of NOARG (Sigma Chemical Co., St. Louis, MO) was administered intraperitoneally $1.5 \mathrm{~h}$ before the hypoxic insult. The reason why we chose the dose of $2 \mathrm{mg} / \mathrm{kg}$ is that, in preliminary experiments, higher doses of NOARG significantly increased mortality during hypoxia ( 3 or $4 \mathrm{mg} / \mathrm{kg}, \mathrm{ca}$. $50 \% ; 8$ or $15 \mathrm{mg} / \mathrm{kg}, \mathrm{ca}$. $100 \%$ ). Even if the pups survived the insult, they looked moribund and appeared to develop the same extent of brain damage compared to the saline-injected littermates. In the posthypoxic treatment group (group $2, n=12$ pairs), $2 \mathrm{mg} / \mathrm{kg}$ of NOARG was given 
Table 1. Percent volume of hypoxic-ischemic brain damage*

\begin{tabular}{lccc}
\hline & $n$ & $\begin{array}{c}\text { Cerebral } \\
\text { cortex }\end{array}$ & Striatum \\
\hline Group 1 (1.5 h prehypoxia) & & & \\
$\quad$ Saline & 8 & $59 \pm 7$ & $50 \pm 9$ \\
NOARG & 8 & $13 \pm 8 \dagger$ & $6 \pm 6 \dagger$ \\
Group 2 (0 h posthypoxia) & & & \\
$\quad$ Saline & 11 & $64 \pm 5$ & $67 \pm 5$ \\
NOARG & 11 & $58 \pm 6$ & $62 \pm 6$ \\
\hline
\end{tabular}

* Percent volume $=$ (sum of ipsilateral damaged area/sum of contralateral area) $\times 100$. Data are mean \pm SE.

$+p<0.01$; significant versus corresponding saline-injected control (Mann-Whitney U test).

immediately after the cessation of hypoxia. Each experimental animal received NOARG dissolved in normal saline $(5 \mathrm{ml} / \mathrm{kg})$, and its paired littermate was administered the same volume of normal saline.

In rats administered NOARG $(n=8)$ or saline $(n=8) 1.5 \mathrm{~h}$ before the hypoxic insult, each rat pup underwent rectal temperature monitoring from $1.5 \mathrm{~h}$ before hypoxia until $24 \mathrm{~h}$ after the cessation of hypoxia at 10 time points $(1.5$ and $0 \mathrm{~h}$ before hypoxia, $1.5 \mathrm{~h}$ after the start of hypoxia, $0,0.5,1,2,3,4$, and $24 \mathrm{~h}$ after hypoxia).

The rat pups were perfusion-fixed with $4 \%$ formaldehyde buffered to $\mathrm{pH} 7.4072 \mathrm{~h}$ after the hypoxic-ischemic insult at 10 $\mathrm{d}$ of age. The pups were anesthetized with pentobarbital $(50 \mathrm{mg} /$ $\mathrm{kg}$ ) intraperitoneally, and perfused with heparinized saline followed by neutral-buffered formaldehyde solution via the left ventricle. Each pump was decapitated after perfusion, and the head was stored in the same fixative at $4^{\circ} \mathrm{C}$ for at least $16 \mathrm{~h}$. Coronal blocks of the brain were processed in a graded series of ethanol and xylene. After embedding in paraffin wax, $8-\mu \mathrm{m}$ thick coronal slices were sectioned every $200 \mu \mathrm{m}$ and stained with hematoxylin-eosin.

Areas of hypoxic-ischemic damage were calculated at six coronal levels (4) selected according to a stereotaxic atlas of the 10d-old rat brain (19). The coronal levels with longitudinal coordinate and anatomic structure were as follows: $\mathrm{A} 7.0 \mathrm{~mm}$ at the nucleus accumbens, $A 5.6 \mathrm{~mm}$ at the caudate-putamen and the anterior commissure, A $4.4 \mathrm{~mm}$ at the globus pallidus, A 3.2 $\mathrm{mm}$ at the anterior tip of the dorsal hippocampus, A $2.0 \mathrm{~mm}$ at the middle of the dorsal hippocampus, and $A 0.8 \mathrm{~mm}$ at the ventral hippocampus. All measurements of area were performed on maps of these six coronal levels, using an image analyzer (LUZEX-2D, Nikon Corporation, Japan) with a magnification factor of about 2200 pixels $/ \mathrm{mm}^{2}$. The measurements included the cerebral cortex in all six coronal planes and the striatum in two coronal planes at A $5.6 \mathrm{~mm}$ and A $4.4 \mathrm{~mm}$, and areas showing hypoxic-ischemic damage in the same region. The percent volume occupied by hypoxic-ischemic necrosis was obtained in the cortex and the striatum by dividing the sum of damaged areas ipsilateral to the carotid ligation by the sum of the contralateral areas of each structure.

The hypoxic-ischemic changes of five hippocampal structures,
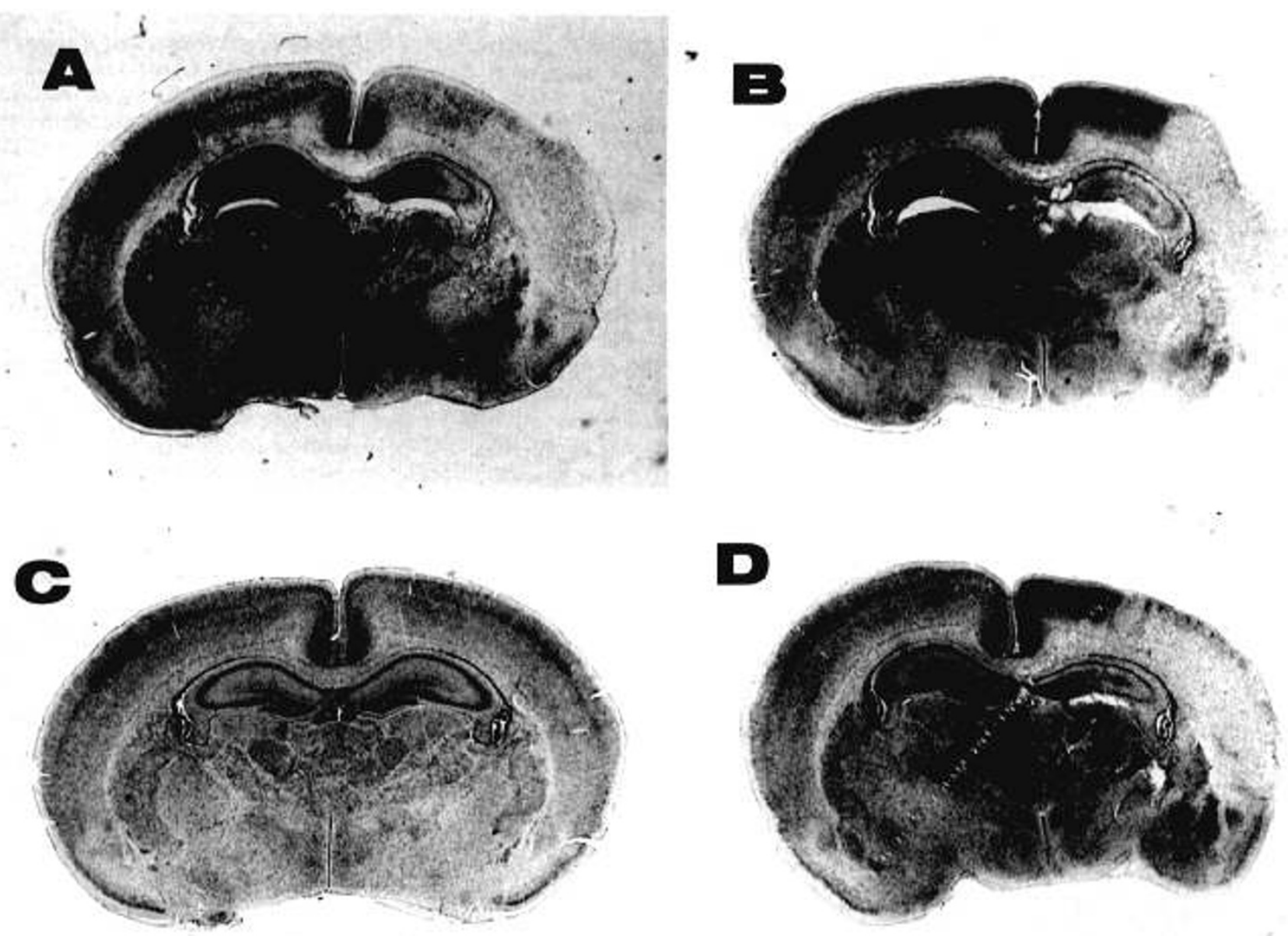

Fig. 1. Coronal brain sections showing the middle of the dorsal hippocampus in the coronal plane A 2.0 mm according to an atlas of 10-d-old rat brain (13). $A$ and $B$ are saline-injected controls $1.5 \mathrm{~h}$ before and immediately after hypoxia, respectively. $C$ and $D$ are pups administered NOARG intraperitoneally $1.5 \mathrm{~h}$ before and immediately after hypoxia, respectively. A neuroprotective effect is observed in $C$. Hematoxylin-eosin stain; original magnification $\times 14.5$. 

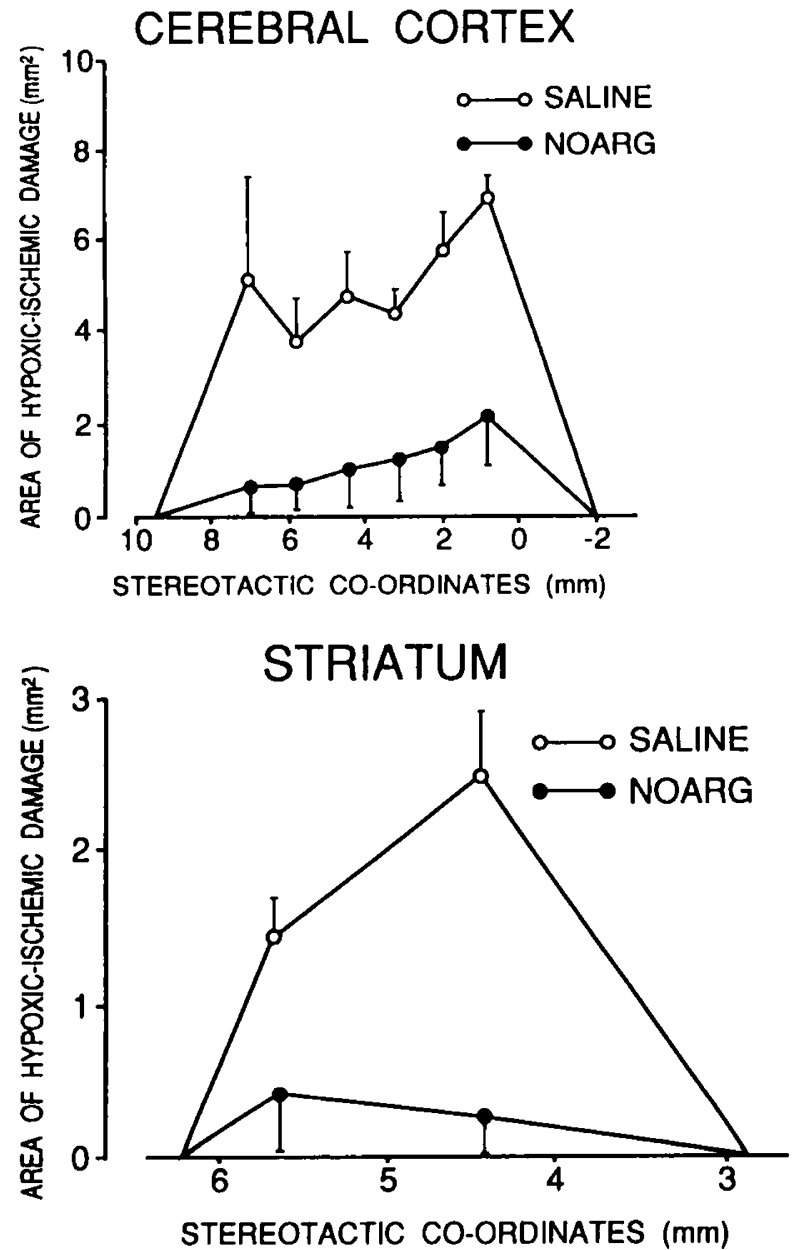

Fig. 2. Amount $\left(\mathrm{mm}^{2}\right)$ of hypoxic-ischemic necrosis in neonates in different coronal planes of the cerebral cortex and striatum in group 1 in which NOARG was administered $1.5 \mathrm{~h}$ before the insult. There are significant differences $(p<0.01$; Mann-Whitney $U$ test) between salineinjected controls and NOARG-treated pups in all coronal planes examined in both cerebral cortex and striatum. Data represent mean $\pm \mathrm{SE}$ ( $n=8$ pairs).

dentate gyrus, CA4, CA3, CA1, and subiculum, in the dorsal hippocampus in the coronal plane at A $2.0 \mathrm{~mm}$ were assessed according to a semiquantitative 4-point scale (4): 0 , no damage; 1 , rare to occasional eosinophilic neurons (approximately less than $10 \%$ ); 2 , moderate number of eosinophilic neurons (approximately 10 to $50 \%$ ); and 3 , frequent eosinophilic neurons (greater than $50 \%$ ). Light microscopic examination was performed with the examiner blinded to the experimental protocol. The mean value from ipsilateral hippocampi evaluated independently was obtained from each animal.

Data are presented as mean $\pm \mathrm{SE}$. The mortality rate of the animals was evaluated by two-tailed Fisher's exact probability test, and differences in body weight and rectal temperature were evaluated by two-tailed unpaired $t$ test. The extent of the hypoxicischemic volume and area in the cortex and the striatum, and that of the neuronal damage score in the hippocampus were not distributed normally; therefore, they were tested by the two-tailed Mann-Whitney $U$ test. A probability of less than 0.05 was considered significant.

\section{RESULTS}

The mortality rates during hypoxia did not differ significantly in the groups with prehypoxic treatment with NOARG $(16.7 \%$, 2 of 12 ) and saline $(25.0 \%, 3$ of 12$)$, or in the groups with posthypoxic treatment with NOARG $(7.1 \%, 1$ of 12$)$ and saline $(0 \%, 0$ of 12$)$. There was no significant body weight difference between NOARG-treated pups and saline-injected controls at $d$ 7 or d 10 ; from $10.5 \pm 0.2 \mathrm{~g}$ on 7 to $12.2 \pm 0.5 \mathrm{~g}$ on $\mathrm{d} 10$ in NOARG-treated pups versus from $10.5 \pm 0.2 \mathrm{~g}$ on $\mathrm{d} 7$ to $11.0 \pm$ $0.3 \mathrm{~g}$ on d 10 in saline-injected controls in group 1 ( $n=8$ pairs), and from $10.3 \pm 0.3 \mathrm{~g}$ on $\mathrm{d} 7$ to $10.5 \pm 0.5 \mathrm{~g}$ on d 10 in NOARGtreated pups versus from $10.3 \pm 0.2 \mathrm{~g}$ on $\mathrm{d} 7$ to $9.8 \pm 0.3 \mathrm{~g}$ on d 10 in saline-injected controls in group 2 ( $n=11$ pairs). Rectal temperatures did not differ between NOARG- and saline-pretreated pups at any points examined.

Cortical and striatal lesions with hypoxic-ischemic changes were sharply demarcated and were easily delineated using the image analyzer. The percent volume of hypoxic-ischemic damage in the cerebral cortex and striatum ipsilateral to the carotid artery ligation relative to the contralateral cerebral cortex and striatum is shown in Table 1. The mean percent volume of hypoxicischemic brain damage of the NOARG-pretreated pups showed $77 \%$ reduction in the cerebral cortex and $87 \%$ reduction in the striatum relative to that of the saline-injected controls. However, there was no protective effect in the NOARG-post-treated pups, both in the cerebral cortex and the striatum (Table 1). The hypoxic-ischemic lesions in the ipsilateral hemisphere were distributed, in order of decreasing damage intensity, in the cerebrum with preservation of a small rim of cortex dorsomedially, the hippocampus, the striatum, the corpus callosum, and the thalamus (Fig. 1), and when NOARG was effective, the protection was seen in all coronal sections examined both in the cerebral cortex and the striatum (Fig. 2).

Hypoxic-ischemic damage of the hippocampus in this current study was so severe that in some of the control rats these neurons showed widespread necrosis and were replaced by vacuoles. Pretreatment with NOARG attenuated the hypoxic-ischemic neuronal damage in all five substructures of the ipsilateral hippocampus, especially in the dentate gyrus and the CAl region. No protective effect was observed with posthypoxic treatment with NOARG in all five substructures (Table 2).

\section{DISCUSSION}

Our results demonstrate that, in the neonatal period, treatment with an inhibitor of NO synthesis before an episode of cerebral

Table 2. Semiquantitative ischemic neuronal scores of the ipsilateral hippocampal substructures in the neonatal hypoxic-ischemic model*

\begin{tabular}{lllllll}
\hline & $n$ & DG & CA4 & CA3 & CA1 & SUB \\
\hline Group 1 (1.5 h prehypoxia) & & & & & & \\
$\quad$ Saline & 8 & $2.9 \pm 0.1$ & $2.5 \pm 0.2$ & $3.0 \pm 0$ & $2.8 \pm 0.2$ & $2.8 \pm 0.2$ \\
$\quad$ NOARG & 8 & $1.3 \pm 0.4 \dagger$ & $0.8 \pm 0.4 \ddagger$ & $1.9 \pm 0.4 \ddagger$ & $0.9 \pm 0.3 \dagger$ & $1.3 \pm 0.4 \ddagger$ \\
Group 2 (0 h posthypoxia) & 11 & $3.0 \pm 0$ & $2.9 \pm 0.1$ & $3.0 \pm 0$ & $2.9 \pm 0.1$ & $3.0 \pm 0$ \\
$\quad$ Saline & 11 & $2.7 \pm 0.1$ & $2.7 \pm 0.1$ & $3.0 \pm 0$ & $2.8 \pm 0.1$ & $2.9 \pm 0.1$ \\
NOARG & &
\end{tabular}

* Abbreviations are: DG, dentate gyrus; SUB, subiculum; CA1-4, cornu ammonis fields 1 to 4 . The number of eosinophilic neurons in each structure was assessed semiquantitatively as follows: 0 , no damage; $1,<10 \% ; 2,10$ to $50 \% ; 3,>50 \%$ eosinophilic neurons. Data are mean \pm SE. $+p<0.01$.

$\ddagger p<0.05$; significant versus corresponding saline-injected control (Mann-Whitney $\mathrm{U}$ test). 
hypoxia-ischemia provides marked protection against brain damage. However, therapy started immediately after the cessation of hypoxia failed to protect against brain damage. These results indicate that NO synthesis in brain tissue plays a critical role in the development of neonatal hypoxic-ischemic brain damage.

Glutamatergic innervation of the striatum (20) and density of NMDA binding sites in the hippocampus (21) peak at around the 7th postnatal day. This transient overinnervation coincides with the enhanced neurotoxicity of microinjected NMDA and the enhancement of hypobaric-ischemic damage in the immature rat brain $(2,22)$. Activated NMDA receptors increase free cytosolic $\mathrm{Ca}^{2+}$, which stimulates NO synthase (23) with binding to calmodulin (24). NO, which is a free radical gas in itself, rapidly reacts with superoxide to form the stable peroxynitrite anion. Once protonated, peroxynitrite decomposes and generates a strong oxidant with reactivity similar to that of the hydroxyl radical (25). In the present model, prevention of the neurotoxicity of the formed free radicals after hypoxic-ischemic damage is one of the neuroprotective effects of the inhibitor of NO synthesis. Allopurinol decreases superoxide radicals by inhibition of xanthine oxidase, and can thereby reduce perinatal hypoxic-ischemic brain damage (26).

Neuronal NADPH diaphorase-containing neurons, which are selectively preserved $1 \mathrm{wk}$ after hypoxic-ischemic injury in neonatal pups (27), are identical to NO synthase-containing neurons (28). NADPH diaphorase-containing neurons are also relatively resistant to damage by low concentrations of NMDA agonists (29). Why these neurons are selectively resistant to neurotoxic insults has not been fully elucidated. The diaphorase activity of NO synthase may be associated with this neuroprotection. In addition, NO synthase-containing neurons are enriched in manganese superoxide dismutase (30) which could be protective by removing a superoxide anion that produces a strong oxidant with NO. Alternatively, the present evidence, which indicates possible effects of $\mathrm{NO}$ in both oxidizing a redox modulatory site consisting of thiol groups on the NMDA receptor-channel complex (31) and decreasing NMDA-mediated increase in intracellular $\mathrm{Ca}^{2+}(32)$, may represent a feedback inhibitory mechanism for NO production. In the presence of high concentrations of NMDA agonists, NADPH diaphorase-containing neurons, which are the source of neurotoxic NO (33), can release large amounts of NO (34) to kill nearby neurons, and may consequently produce widespread neuronal damage (29).

Glyceraldehyde-3-phosphate dehydrogenase, an important enzyme in the glycolytic pathway, is inactivated by ADP-ribosylation induced by NO (35). Because glucose supplementation is beneficial to the perinatal brain exposed to hypoxia-ischemia $(36,37)$, in contrast to adult animals, inhibition of NO synthesis may preserve the glycolytic pathway during the hypoxic-ischemic insult and may ameliorate the ultimate brain damage. Alternatively, NO inhibits both mitochondrial enzymes including complex 1 (NAD[P]H:ubiquinone oxidoreductase), complex 2 (succinate:ubiquinone oxidoreductase) and aconitase leading to subsequent inhibition of mitochondrial respiration, and the ratelimiting enzyme in DNA replication, ribonucleotide reductase, leading to inhibition of DNA synthesis in the macrophage effector cells (38). All of these enzymes have a catalytically active nonheme iron-sulfur center which binds to NO leading to intracellular iron loss. Therefore, NO could mediate cytotoxicity by inhibiting mitochondrial functions in the hypoxic-ischemic brain (present study), as well as that of macrophages (39). There are at least two distinct $\mathrm{NO}$ synthases. One is the constitutive, $\mathrm{Ca}^{2+}$ calmodulin-dependent enzyme, which releases NO for short periods in response to receptor activation in neurons, endothelial cells (40), and possibly in astrocytes (41). The other is the inducible form, which is induced by immunological stimuli and synthesizes $\mathrm{NO} \mathrm{Ca}^{2+}$ independently over a period of hours to days in macrophages (42). Both NO synthases are soluble, require NADPH, form citrulline as a coproduct, and are competitively inhibited by L-arginine analogs. Recently, it was elucidated that glial cells of the central nervous system could express an inducible form of NO synthase, which may contribute to hypoxic-ischemic brain damage (43). The reason why in several studies $(13,14$, 16) it failed to protect the brain from the ischemic insult with $L$ arginine analogs administered for a short time may be that the inducible form of NO synthase could not be inhibited completely. However, the reason why prehypoxic treatment with one dose of NOARG could protect against hypoxic-ischemic brain damage in our study is unknown.

A possible explanation for the lack of effect of NOARG administered after the insult is that NO synthase activated by hypoxic stimuli could not generate NO because of the lack of molecular oxygen, which both constitutive and inducible NO synthases incorporate into NO. However, NO synthases are at once fully activated upon return of the rat to room air, and can immediately generate a burst of NO, which cannot be blocked by NOARG. Effective levels of NOARG would not be reached because the peritoneal vascular beds are vasoconstricted and absorption is slow. The lack of posthypoxic effect of the NO synthase inhibitor is not in accord with the neuroprotective effect of posthypoxic treatment with the NMDA receptor antagonist, MK-801, in another neonatal rat model of hypoxic-ischemic brain damage (4).

Hypothermia can reduce ischemic brain damage both in adult rats (44) and immature rats (45). Postischemic treatment with NOARG reduces the area of cerebral infarction in adult mice (11) and rats (12) subjected to middle cerebral artery occlusion. $N^{G}$-nitro-L-arginine methyl ester, an inhibitor of NO synthesis, could reduce body temperature. When the body temperature was maintained at $37^{\circ} \mathrm{C}, N^{\mathrm{G}}$-nitro-L-arginine methyl ester administered $30 \mathrm{~min}$ before and $30 \mathrm{~min}$ after middle cerebral artery occlusion could not protect against ischemic damage in the cerebral hemisphere (13). In our study, each pup administered either NOARG or saline was kept in an atmosphere maintained at $37^{\circ} \mathrm{C}$ from soon after carotid artery ligation to $1 \mathrm{~h}$ after the hypoxic insult. There were no significant differences in rectal temperature between NOARG- and saline-pretreated pups from the time of treatment until $24 \mathrm{~h}$ after the cessation of hypoxic exposure. Therefore, the possible induction of hypothermia by NOARG is not able to explain its protective effect in this model of neonatal hypoxic-ischemic brain damage.

NOARG is reported to cause a pressor effect and bradycardia (46), and to decrease cerebral blood flow (47). It is not feasible to cannulate vessels in these small animals; therefore, whether circulatory effects of NOARG contribute to the neuroprotection is not clear. The arginine analogs could also inhibit the mitochondrial electron transport system by inhibiting the reduction of ferric cytochrome C (48). However, if NOARG had decreased the cerebral blood flow and inhibited the mitochondrial electron transport, it could have worsened the brain damage in our model.

\section{REFERENCES}

1. Vannucci RC 1990 Experimental biology of cerebral hypoxia-ischemia: relation to perinatal brain damage. Pediatr Res 27:317-326

2. McDonald JW, Johnston MV 1990 Physiological and pathophysiological roles of excitatory amino acids during central nervous system development. Brain Res Rev 15:41-70

3. Ikonomidou C, Mosinger JL, Shahid Salles K, Labruyere J, Olney JW 1989 Sensitivity of the developing rat brain to hypobaric/ischemic damage parallels sensitivity to N-methyl-aspartate neurotoxicity. J Neurosci 9:2809-2818

4. Hattori H, Morin AM, Schwartz PH, Fujikawa DG, Wasterlain CG 1989 Posthypoxic treatment with MK-801 reduces hypoxic-ischemic damage in the neonatal rat. Neurology 39:713-718

5. Palmer RMJ, Ashton DS, Moncada S 1988 Vascular endothelial cells synthesize nitric oxide from L-arginine. Nature 333:664-666

6. Knowles RG, Palacios M, Palmer RMJ, Moncada S 1989 Formation of nitric oxide from L-arginine in the central nervous system: a transduction mechanism for stimulation of the soluble guanylate cyclase. Proc Natl Acad Sci USA 86:5159-5162

7. Garthwaite J, Garthwaite G, Palmer RMJ, Moncada S 1989 NMDA receptor activation induces nitric oxide synthesis from arginine in rat brain slices. Eur J Pharmacol 172:413-416

8. Dawson VL, Dawson TM, London ED, Bredt DS, Snyder SH 1991 Nitric 
oxide mediates glutamate neurotoxicity in primary cortical cultures. Proc Natl Acad Sci USA 88:6368-6371

9. Moore PK, al-Swayeh OA, Chong NWS, Evans RA, Gibson A 1990 L-N ${ }^{\mathrm{C}}$. Nitroarginine, a novel, L-arginine-reversible inhibition of endothelium-dependent vasodilatation in vitro. Br J Pharmacol 99:408-412

10. Dwyer MA, Bredt DS, Snyder SH 1991 Nitric oxide synthase: irreversible inhibition by $\mathrm{L}-\mathrm{N}^{\circ}$-nitroarginine in brain in vitro and in vivo. Biochem Biophys Res Commun 176:1136-1141

11. Nowicki JP, Duval D, Poignet H, Scatton B 1991 Nitric oxide mediates neuronal death after focal cerebral ischemia in the mouse. Eur J Pharmacol 204:339-340

12. Nagafugi T, Matsui T, Koide T, Asano T 1992 Blockade of nitric oxide formation by $\mathrm{N}^{\mathrm{w}}$-nitro-L-arginine mitigates ischemic brain edema and subsequent cerebral infarction in rats. Neurosci Lett 147:159-162

13. Dawson DA, Kusumoto K, Graham DI, McCulloch J, Macrae IM 1992 Inhibition of nitric oxide synthesis does not reduce infarct volume in a rat model of focal cerebral ischemia. Neurosci Lett 142:151-154

14. Weissman BA, Kadar T, Brandeis R, Shapira S $1992 \mathrm{~N}^{\mathrm{G}}$-Nitro-L-arginine enhances neuronal death following transient forebrain ischemia in gerbils. Neurosci Lett 146:139-142

15. Buisson A, Plotkine M, Boulu RG 1992 The neuroprotective effect of a nitric oxide inhibitor in a rat model of focal cerebral ischaemia. Br J Pharmaco 106:766-767

16. Yamamoto S, Golanov EV, Berger SB, Reis DJ 1992 Inhibition of nitric oxide synthesis increases focal ischemic infarction in rat. J Cereb Blood Flow Metab 12:717-726

17. Rice JE, Vannucci RC, Brierley JB 1981 The influence of immaturity on hypoxic-ischemic brain damage in the rat. Ann Neurol 9:131-141

18. Hattori H, Wasterlain CG 1990 Excitatory amino acids in the developmenta brain: ontogeny, plasticity and excitotoxicity. Pediatr Neurol 6:219-228

19. Sherwood NM, Timiras PS 1970 A Stereotaxic Atlas of the Developing Rat Brain. University of California Press, Berkley, CA, pp 15-75

20. Greenamyre T, Penny JB, Young AB, Hudson C, Silverstein FS, Johnston MV 1987 Evidence for transient perinatal glutamatergic innervation of globus pallidus. J Neurosci 7:1022-1030

21. Tremblay E, Roisin MP, Represa A 1988 Transient increased density of NMDA binding sites in the developing rat hippocampus. Brain Res 461:393-396

22. McDonald JW, Silverstein FS, Johnston MV 1988 Neurotoxicity of $\mathrm{N}$-methylD-aspartate is markedly enhanced in developing rat central nervous system. Brain Res 459:200-203

23. Kiedrowski L, Costa E, Wroblewski JT 1992 Glutamate receptor agonist stimulate nitric oxide synthase in primary cultures of cerebellar granule cells. J Neurochem 58:335-341

24. Bredt DS, Snyder SH 1990 Isolation of nitric oxide synthase, a calmodulinrequiring enzyme. Proc Natl Acad Sci USA 87:682-685

25. Beckman JS, Beckman TW, Chen J, Marshall PA, Freeman BA 1990 Apparen hydroxyl radical production by peroxynitrite: implications for endothelia injury from nitric oxide and superoxide. Proc Natl Acad Sci USA 87:16201624

26. Palmer C, Vannucci RC, Towfighi J 1990 Reduction of perinatal hypoxicischemic brain damage with allopurinol. Pediatr Res 27:332-336

27. Ferriero DM, Arcavi LJ, Sagar SM, McIntosh TK, Simon RP 1988 Selective sparing of NADPH-diaphorase neurons in neonatal hypoxia-ischemia. Ann Neurol 24:670-676
28. Hope BT, Michael GJ, Knigge KM, Vincent SR 1991 Neuronal NADPH diaphorase is a nitric oxide synthase. Proc Natl Acad Sci USA 88:2811-2814

29. Koh J, Choi DW 1988 Vulnerability of cultured cortical neurons to damage by excitotoxins: differential susceptibility of neurons containing NADPHdiaphorase. J Neurosci 8:2153-2163

30. Inagaki S Suzuki K. Taniguchi N, Takagi H 1991 Localization of Mnsuperoxide dismutase (Mn-SOD) in cholinergic and somatostatin-containing neurons in the rat neostriatum. Brain Res 549:174-177

31. Lei SZ, Pan Z, Aggarwal SK, Chen HV, Hartman J, Sucher NJ, Lipton SA 1992 Effect of nitric oxide production on the redox modulatory site of the NMDA receptor-channel complex. Neuron 8:1087-1099

32. Hoyt KR, Tang L, Aizenman E, Reynolds IJ 1992 Nitric oxide modulates NMDA-induced increase in intracellular $\mathrm{Ca}^{2+}$ in cultured rat forebrain neurons. Brain Res 592:310-316

33. Dawson TM, Bredt DS, Fotuhi M, Hwang PM, Snyder SH 1991 Nitric oxide synthase and neuronal NADPH diaphorase are identical in brain and peripheral tissues. Proc Natl Acad Sci USA 88:7797-7801

34. Garthwaite J, Charles SL, Chess-Williams R 1988 Endothelium-derived relaxing factor release on activation of NMDA receptors suggests role as intercellular messenger in the brain. Nature 336:385-388

35. Molina y Vedia L, McDonald B, Reep B, Brüne B, Di Silvio M, Billiar TR, Lapetina EG 1992 Nitric oxide-induced S-nitrosylation of glyceraldehyde-3phosphate dehydrogenase inhibits enzymatic activity and increase endogenous ADP-ribosylation. J Biol Chem 267:24929-24932

36. Hattori H, Wasterlain CG 1990 Posthypoxic glucose supplement reduces hypoxic-ischemic brain damage in the neonatal rat. Ann Neurol 28:122-128

37. Vannuci RC, Yager JY 1992 Glucose, lactic acid, and perinatal hypoxicischemic brain damage. Pediatr Neurol 8:3-12

38. Dawson TM, Dawson VL, Snyder SH 1992 A novel neuronal messenger molecule in brain: the free radical, nitric oxide. Ann Neurol 32:297-31

39. Marletta MA 1989 Nitric oxide: biosynthesis and biological significance. Trends Biol Sci 14:488-492

40. Bredt DS, Hwang PM, Glatt CE, Lowenstein C, Reed RR, Snyder SH 1991 Cloned and expressed nitric oxide synthase structurally resembles cytochrome P-450 reductase. Nature 351:714-718

41. Murphy S, Minor Jr RL, Welk G, Harrison DG 1990 Evidence for an astrocytederived vasorelaxing factor with properties similar to nitric oxide. J Neurochem 55:349-351

42. Moncada S, Palmer RMJ, Higgs EA 1991 Nitric oxide: physiology, pathophysiology and pharmacology. Pharmacol Rev 43:109-142

43. Galea E, Feinstein DL, Reis DJ 1992 Induction of calcium-independent nitric oxide synthase activity in primary rat glial cultures. Proc Natl Acad Sci USA 89:10945-10949

44. Onesti ST, Baker CJ, Sun PP, Solomon RA 1991 Transient hypothermia reduces focal ischemic brain injury in the rat. Neurosurgery 29:369-373

45. McDonald JW, Chen CK. Trescher WH, Johnston MV 1991 The severity of excitotoxic brain injury is dependent on brain temperature in immature rat. Neurosci Lett 126:83-86

46. Du Z, Dusting GJ, Woodman OL 1992 Baroreceptor reflexes and vascular reactivity during inhibition of nitric oxide synthesis in conscious rabbits. Eur J Pharmacol 214:21-26

47. Wang Q, Paulson OB, Lassen NA 1992 Effect of nitric oxide blockade by $N^{G}$. nitro-L-arginine on cerebral blood flow response to changes in carbon dioxide tension. J Cereb Blood Flow Metab 12:947-953

48. Peterson DA, Peterson DC, Archer S, Weir EK 1992 The non specificity of specific nitric oxide synthase inhibitors. Biochem Biophys Res Commun 187:797-801 